\title{
Intelligence quotient-adjusted memory impairment is associated with abnormal single photon emission computed tomography perfusion
}

\section{Citation}

Rentz, Dorene M., Terri J. Huh, Lisa M. Sardinha, Erin K. Moran, John A. Becker, Kirk R. Daffner, Reisa A. Sperling, and Keith A. Johnson. 2007. "Intelligence Quotient-adjusted Memory Impairment Is Associated with Abnormal Single Photon Emission Computed Tomography Perfusion." J. Inter. Neuropsych. Soc. 13, no. 05: 821-831.

\section{Published Version}

10.1017/S1355617707071056

\section{Permanent link}

http://nrs.harvard.edu/urn-3:HUL.InstRepos:12605387

\section{Terms of Use}

This article was downloaded from Harvard University's DASH repository, and is made available under the terms and conditions applicable to Other Posted Material, as set forth at http:// nrs.harvard.edu/urn-3:HUL.InstRepos:dash.current.terms-of-use\#LAA

\section{Share Your Story}

The Harvard community has made this article openly available.

Please share how this access benefits you. Submit a story.

Accessibility 


\title{
Intelligence quotient-adjusted memory impairment is associated with abnormal single photon emission computed tomography perfusion
}

\author{
DORENE M. RENTZ, ${ }^{1}$ TERRI J. HUH, ${ }^{2}$ LISA M. SARDINHA, ${ }^{1}$ ERIN K. MORAN, ${ }^{3}$ \\ JOHN A. BECKER, ${ }^{3}$ KIRK R. DAFFNER, ${ }^{1}$ REISA A. SPERLING,${ }^{1,4}$ AND KEITH A. JOHNSON ${ }^{1,3,4}$ \\ ${ }^{1}$ Department of Neurology, Brigham and Women's Hospital, Harvard Medical School, Boston, Massachusetts \\ ${ }^{2}$ Department of Psychiatry, University of California, San Francisco, California \\ ${ }^{3}$ Department of Radiology, Massachusetts General Hospital, Harvard Medical School, Boston, Massachusetts \\ ${ }^{4}$ Department of Neurology, Massachusetts General Hospital, Harvard Medical School, Boston, Massachusetts \\ (Received October 2, 2006; Final Revision March 16, 2007; Accepted March 16, 2007)
}

\begin{abstract}
Cognitive reserve among highly intelligent older individuals makes detection of early Alzheimer's disease (AD) difficult. We tested the hypothesis that mild memory impairment determined by IQ-adjusted norms is associated with single photon emission computed tomography (SPECT) perfusion abnormality at baseline and predictive of future decline. Twenty-three subjects with a Clinical Dementia Rating (CDR) score of 0, were reclassified after scores were adjusted for IQ into two groups, 10 as having mild memory impairments for ability (IQ-MI) and 13 as memory-normal (IQ-MN). Subjects underwent cognitive and functional assessments at baseline and annual follow-up for 3 years. Perfusion SPECT was acquired at baseline. At follow-up, the IQ-MI subjects demonstrated decline in memory, visuospatial processing, and phonemic fluency, and 6 of 10 had progressed to a CDR of 0.5 , while the IQ-MN subjects did not show decline. The IQ-MI group had significantly lower perfusion than the IQ-MN group in parietal/precuneus, temporal, and opercular frontal regions. In contrast, higher perfusion was observed in IQ-MI compared with IQ-MN in the left medial frontal and rostral anterior cingulate regions. IQ-adjusted memory impairment in individuals with high cognitive reserve is associated with baseline SPECT abnormality in a pattern consistent with prodromal AD and predicts subsequent cognitive and functional decline. (JINS, 2007, 13, 821-831.)
\end{abstract}

Keywords: Aging, Dementia risk, Cognitive decline, Alzheimer's disease, Imaging, Mild cognitive impairment

\section{INTRODUCTION}

As disease-modifying treatments become available, the best hope for altering the progression of Alzheimer's disease $(\mathrm{AD})$ is the identification of individuals in the very earliest stages of the disease. However, the task of differentiating normal, age-related memory changes from early symptoms of $\mathrm{AD}$ is difficult, particularly among individuals with high cognitive reserve.

It has been widely acknowledged that the trajectory of clinical decline leading to AD passes through a stage of mild cognitive impairment (MCI; Petersen et al., 1999; Winblad et al., 2004) that may begin years before overt demen-

Correspondence and reprint requests to: Dorene M. Rentz, PsyD, Division of Cognitive and Behavioral Neurology, Brigham and Women's Hospital, 221 Longwood Avenue, Boston, MA 02115, USA. E-mail: drentz@partners.org tia. Recent reports indicate that the neuropathologic changes of $\mathrm{AD}$, including neurofibrillary tangles and amyloid plaques, not only occur in MCI (Markesbery et al., 2006; Petersen et al., 2006) but are also found in some individuals who are clinically normal (Bennett et al., 2006; Davis et al., 1999; Morris et al., 1996, 2001; Price \& Morris, 1999; Storandt et al., 2006). While diagnostic and imaging markers are being developed to detect early pathologic changes during life (Andreasen \& Blennow, 2005; Klunk et al., 2003, 2004; Schoonenboom et al., 2005), clinical performance on tests of memory remains the most widely accepted marker of prodromal AD in at-risk individuals (Albert et al., 2001; Albert, 2002).

However, highly intelligent individuals with higher cognitive reserve (Stern, 2002, 2006) tend to perform well on cognitive tests despite neuropathological evidence of advancing AD pathology (Mortimer et al., 2005; Naugle et al., 
1990; Richards \& Deary, 2005; Whalley et al., 2004). Neuroimaging studies of individuals with high cognitive reserve found that these individuals tend to recruit alternate neural networks or establish compensatory pathways in response to neuropsychological task demands (Cabeza et al., 2002; Mortimer et al., 2005; Stern et al., 2005). To account for the influence of cognitive reserve on neuropsychological test performance, we explored whether IQ-adjustments could detect early memory changes (IQ-MI) possibly masked by cognitive reserve and whether single photon emission computed tomography (SPECT) perfusion differed between groups with normal and impaired IQ-adjusted scores.

Functional neuroimaging methods such as positron emission tomography (PET) and SPECT are used increasingly in the clinical evaluation of individuals with memory impairment. These methods may have limited specificity with respect to non-AD causes of dementia (Rutschmann \& Matchar, 2002); however, image abnormalities have been reported in the prodromal phase of $\mathrm{AD}$, reflecting early changes in brain physiology that have now been shown to portend further decline (Johnson et al., 1998, 2007; Mungas et al., 2002). For example, temporoparietal hypoperfusion has been reported in nondemented subjects with cognitive impairment who later converted to AD (Chetelat et al., 2003; Johnson \& Albert, 2000; Nestor et al., 2003), and in asymptomatic carriers of the PS1 gene mutation with autosomal dominant inheritance, which causes early onset AD (Johnson et al., 2001). In this study, our objective was to investigate whether individuals identified as IQ-MI showed evidence of functional imaging abnormalities at baseline and a higher likelihood of subsequent declines in cognition and daily living skills. We hypothesized that IQ-MI subjects with a Clinical Dementia Rating score of 0 (CDR0) at baseline would show SPECT hypoperfusion in temporoparietal regions consistent with those subjects who later converted to AD (Johnson \& Albert, 2000). We, furthermore, hypothesized that IQ-MI subjects would be more likely to decline on neuropsychological and functional measures (CDR) 3 years later than those without evidence of impairment after IQ-adjustment (IQ-MN).

\section{METHODS}

\section{Research Participants}

Subjects were recruited from a cohort of 293 communitydwelling individuals who answered newspaper advertisements to participate in an aging and Alzheimer's disease study at Brigham and Women's Hospital. The study was annually approved by The Institutional Review Board, Partners Human Research Committee, in accordance with the Helsinki Declaration, and participants gave informed consent. All subjects were living independently and agreed to return for follow-up testing. They underwent a series of neuropsychological tests commonly used in the assessment of older individuals (Rentz \& Weintraub, 1999), which included the Blessed Dementia Rating Scale (BDS; Blessed et al., 1968); Geriatric Depression Scale (GDS; Yesavage et al., 1983); American National Adult Reading Test (AMNART; Ryan \& Paolo, 1992); Clinical Dementia Rating Scale (CDR; Morris, 1993); word generation to the letters F, A, and S (Monsch et al., 1992); category fluency to animals, fruits, and vegetables (CAT; Monsch et al., 1992); the 6-trial version of the Selective Reminding Test (SRT; Masur et al., 1989); the 60-item version of the Boston Naming Test (BNT; Kaplan et al., 1983; Tombaugh \& Hubley, 1997); and the Visual Form Discrimination Test (VFDT; Benton et al., 1983). They also underwent a comprehensive medical and psychiatric interview as well as a neurological evaluation to rule out any major neurological disorders that might contribute to cognitive dysfunction. None of the participants had a history of alcoholism, drug abuse, or evidence of neurological, medical, or psychiatric illness.

From a total of 81 subjects who underwent SPECT, 23 subjects were selected for this analysis because they met the following inclusion criteria: (1) a CDR score of 0, (2) an estimated IQ of 120 or greater on the AMNART, (3) baseline scores on the BDS of less than 2, (4) a GDS score in the normal range (score $<11$ ), (5) cognitive test scores within $1.5 S D$ from the mean on the basis of published test norms adjusted for age and education (see Table 1), and (6) two $\mathrm{E} 3$ alleles because $\mathrm{E} 4$ has been associated with increased risk for the development of $\mathrm{AD}$ and is also associated with regionally reduced cerebral metabolism (Caselli et al., 2004; Reiman et al., 2001, 2005; Small, 2002). We also excluded all subjects with an E2 allele as this allele has been linked to a reduced risk for AD (Hyman et al., 1996). All 23 subjects had a structural magnetic resonance imaging scan within 3 months of their SPECT scan.

\section{Estimating Cognitive Reserve}

The cognitive reserve hypothesis postulates that individuals with higher reserve may have AD pathology but not exhibit cognitive impairment (Bennett et al., 2006; Stern et al., 2005). Factors such as education (Stern et al., 1994), occupational status (Stern et al., 1995), life activities (Scarmeas et al., 2003), innate intelligence (Alexander et al., 1997), or a combination of these factors (Andel et al., 2006; Stern et al., 2005) are thought to compose aspects of cognitive reserve that help individuals acquire and use the set of skills necessary to cope with pathology and, therefore, perform normally on cognitive tasks. In this study, we chose to estimate cognitive reserve using a word-reading estimate of premorbid ability, namely the AMNART (Ryan \& Paolo, 1992). The AMNART is a reading list of 50 irregular words that are scored correct if pronounced accurately. IQ is determined based on an error score. Numerous studies found pronunciation accuracy to correlate highly with measured intelligence on the Wechsler Adult Intelligence ScaleRevised Verbal IQ (WAIS-R VIQ; $r=.80$ to .95 ; Friedman et al., 1992; Nelson \& O'Connell, 1978; Ryan \& Paolo, 1992; Wiens et al., 1993), and it has shown adequate relia- 
Table 1. Baseline and follow-up data for IQ-MN and IQ-MI groups

\begin{tabular}{|c|c|c|c|c|c|c|c|}
\hline \multirow[b]{2}{*}{ Gender } & \multirow[t]{2}{*}{$\begin{array}{c}\text { Normative } \\
\text { Cutoff }\end{array}$} & \multirow[t]{2}{*}{$\begin{array}{l}\text { IQ-Adj. } \\
\text { Cutoff }\end{array}$} & \multicolumn{2}{|c|}{$\begin{array}{l}\text { IQ-MN } \\
N=13\end{array}$} & \multicolumn{2}{|c|}{$\begin{array}{c}\text { IQ-MI } \\
N=10\end{array}$} & \multirow[b]{2}{*}{$p$ value } \\
\hline & & & & & & & \\
\hline Male & & & & & & & .45 \\
\hline Female & & & & & & & \\
\hline Demographics & & & $M$ & $S D$ & $M$ & $S D$ & \\
\hline Age & & & 69.3 & 4.8 & 71.8 & 4.2 & .21 \\
\hline Years of education & & & 17.0 & 2.4 & 14.7 & 2.9 & .06 \\
\hline AMNART IQ & & & 127.4 & 3.5 & 124.9 & 3.9 & .13 \\
\hline GDS & & & 2.9 & 2.5 & 3.7 & 3.0 & .46 \\
\hline Blessed IMC & & & .38 & .7 & .60 & .7 & .45 \\
\hline \multicolumn{8}{|l|}{ Cognitive tests } \\
\hline \multicolumn{8}{|l|}{ FAS } \\
\hline Baseline & $<31$ & $<44$ & 46.2 & 12.0 & 48.9 & 10.8 & .57 \\
\hline Follow-up & & & 56.2 & 15.8 & 47.5 & 12.5 & .17 \\
\hline \multicolumn{8}{|l|}{ CAT } \\
\hline Baseline & $<38$ & $<50$ & 51.1 & 4.6 & 50.0 & 5.8 & .63 \\
\hline Follow-up & & & 53.2 & 6.4 & 48.6 & 7.6 & .13 \\
\hline \multicolumn{8}{|l|}{ BNT } \\
\hline Baseline & $<44$ & $<55$ & 57.7 & 2.1 & 56.3 & 2.5 & .16 \\
\hline Follow-up & & & 58.5 & 1.4 & 57.2 & 2.7 & .16 \\
\hline \multicolumn{8}{|l|}{ VFDT } \\
\hline Baseline & $<25$ & $<29$ & 31.0 & .9 & 30.5 & 1.4 & .30 \\
\hline Follow-up & & & 31.6 & .7 & 29.3 & 3.1 & $.01 *$ \\
\hline \multicolumn{8}{|l|}{ SRT-TR } \\
\hline Baseline & $<33$ & $<47$ & 51.2 & 5.7 & 44.1 & 5.9 & $.01 *$ \\
\hline Follow-up & & & 53.2 & 7.4 & 40.7 & 6.3 & $.00 *$ \\
\hline \multicolumn{8}{|l|}{ SRT-LTS } \\
\hline Baseline & $<22$ & $<42$ & 44.7 & 11.8 & 30.4 & 9.5 & $.01 *$ \\
\hline Follow-up & & & 45.5 & 11.5 & 24.7 & 10.5 & $.00 *$ \\
\hline \multicolumn{8}{|l|}{ SRT-LTR } \\
\hline Baseline & $<18$ & $<37$ & 42.0 & 10.9 & 27.7 & 9.0 & $.00 *$ \\
\hline Follow-up & & & 43.6 & 11.8 & 22.2 & 9.2 & $.00 *$ \\
\hline \multicolumn{8}{|l|}{ SRT-CLTR } \\
\hline Baseline & $<4$ & $<24$ & 35.2 & 11.6 & 24.0 & 8.7 & $.02 *$ \\
\hline Follow-up & & & 36.5 & 13.1 & 13.9 & 9.6 & $.00 *$ \\
\hline \multicolumn{8}{|l|}{ SRT-DR } \\
\hline Baseline & $<3$ & $<7$ & 8.2 & 2.0 & 5.5 & 2.2 & $.01 *$ \\
\hline Follow-up & & & 8.6 & 2.0 & 5.7 & 1.6 & $.00 *$ \\
\hline \multicolumn{8}{|l|}{ SRT-DR30 } \\
\hline Baseline & $<3$ & $<7$ & 9.0 & 1.9 & 6.9 & 2.5 & $.03 *$ \\
\hline Follow-up & & & 9.3 & 1.8 & 6.6 & 2.1 & $.00 *$ \\
\hline \multicolumn{8}{|l|}{ SRT-MC30 } \\
\hline Baseline & $<11$ & $<11$ & 11.8 & 6 & 11.1 & .7 & $.01 *$ \\
\hline Follow-up & & & 12.0 & .0 & 11.5 & .7 & $.02 *$ \\
\hline
\end{tabular}

Note. $\mathrm{MN}=$ memory normal; $\mathrm{MI}=$ memory impaired; AMNART = American National Adult Reading Test estimated Verbal IQ; GDS = Geriatric Depression Scale; IMC = Information, Memory, and Concentration subtest of the Blessed Dementia Rating Scale; $\mathrm{FAS}=$ word generation to the letters $\mathrm{F}, \mathrm{A}$, and $\mathrm{S} ; \mathrm{CAT}=$ Word generation to the categories animals, vegetables, and fruits; BNT $=$ Boston Naming Test; VFDT = Visual Form Discrimination Test; SRT $=$ Selective Reminding Test; TR = Total Recall on SRT; LTS = Long-Term Storage on SRT; LTR = Long-Term Retrieval on SRT; CLTR = Continuous Long-Term Retrieval on SRT; DR = 10-min Delayed Recall on the SRT; DR30 $=30$-min Delayed Recall on the SRT; MC30 $=30$-min Recognition on the SRT. * $p<.05$. Cutoff scores were calculated at $1.5 \mathrm{SD}$ below the mean and the normative reference groups were as follows: FAS and CAT (Monsch et al., 1992), BNT (Tombaugh and Hubley, 1997), VFDT (Benton et al., 1983), and SRT (Masur et al., 1989).

bility and stability in healthy elders and questionable/mild dementia when used in a longitudinal epidemiological study (Schmand et al., 1998). Although some studies have successfully used a combination of factors to constitute a cog- nitive reserve index (Stern et al., 2005), we chose a single measure of premorbid IQ because other studies found this method more sensitive to the neurophysiological effects of $\mathrm{AD}$ than other demographic variables (Alexander et al., 
1997) or a combination of word reading with demographic variables (Bright et al., 2002). Also, an IQ estimate proposes to index higher levels of native ability when subjects do not have the advantages of education (Satz, 1993; Schmand et al., 1997). In a previous study, we explored whether education-adjustments were equally predictive of progression to MCI as IQ-adjustments, and found that education-adjustments were 8.8 times less sensitive at predicting progression to MCI than IQ-adjustments (Rentz et al., 2004). This finding was due to the fact that many of the women in this aged cohort had superior levels of premorbid intelligence but were not well educated. However, we recognize that use of the AMNART as a proxy of cognitive reserve is not perfect for all subjects, particularly those with reading difficulties or non-English speaking participants (O'Carroll, 1995; Storandt et al., 1995). Therefore, all participants in this study were English speaking and had no history of learning disabilities.

At entry, test scores were adjusted for IQ in the following manner: the "mean" value of the published norms was raised to match the individual's IQ level in a method previously described (Rentz et al., 2004). Adjustments were based on the WAIS-R IQ standardization sample in which the mean IQ of the population is 100 and the standard deviation is 15 . IQ scores that were between 120 and 129 are approximately 1.7 SD above the population mean of 100. IQ scores that were equal to or greater than 130 are approximately $2 S D$ above the mean. If the estimated AMNART IQ was $\geq 120$ but $\leq 129$, the normative mean was adjusted upward by 1.7 $S D$ and a new adjusted mean was established for this IQ range. If the estimated AMNART IQ was $\geq 130$, the normative mean was adjusted upward by $2 S D$ and a new adjusted mean was established for this IQ range. Since Petersen et al. (1999) demonstrated that a 1.5 SD cutoff below age-appropriate mean scores accurately predicted decline to $\mathrm{AD}$, we applied this $1.5 \mathrm{SD}$ below the mean cutoff to our IQ-adjusted norms to designate an abnormal score. The cutoff scores used in this study were identical to those previously reported (Rentz et al., 2004).

Based on normal or abnormal test performances adjusted for IQ, subjects were placed into one of two groups: IQ-MN (memory normal), those subjects who scored in the normal range for IQ across all tests and were predicted to remain stable over 3 years; IQ-MI (memory impaired), those subjects who scored in the abnormal range for IQ on at least one subtest of the SRT, scored normally for their ability on all other tests of attention, executive function (i.e., word fluency, language, and visuospatial perception), and were predicted to decline over 3 years. We selected IQ-adjustments in memory only because memory is the earliest symptom of prodromal AD and the SRT has been shown to be a particularly sensitive indicator of subtle impairment that is predictive of decline over time (Hall et al., 2000; Masur et al., 1990). We also controlled for the potential of intraindividual variability in neuropsychological performance by including only those subjects who scored within $1.5 S D$ from the mean on all cognitive tasks except memory. None of the subjects in this study had a diagnosis of dementia, even in the earliest stages.

After IQ-adjustments, 10 of the 23 subjects were reclassified as memory impaired (IQ-MI) and 13 subjects remained within the normal range (IQ-MN). There were no statistically significant differences between groups in age, education, estimated AMNART IQ, GDS, or Information, Memory, and Concentration subtest of the Blessed Dementia Rating Scale (see Table 1).

A total of 5 of the IQ-MN and 5 of the IQ-MI subjects demonstrated minimal or mild increased $\mathrm{T} 2$ signal in white matter consistent with small vessel cerebrovascular changes. None of the subjects had evidence of large vessel infarcts or other structural lesions. Mild atrophy was noted on the clinical read in 2 of the IQ-MN and 2 of the IQ-MI subjects.

Subjects underwent annual neuropsychological evaluations for 3 years. A reliable informant, who lived with or near the subject was also administered a structured interview as part of the CDR (Morris, 1993).

The primary variable of interest was pattern of SPECT perfusion at baseline. The secondary variable of interest was degree of cognitive and functional decline from baseline.

\section{SPECT Image Acquisition}

Images were acquired $20 \mathrm{~min}$ after intravenous injection of $20 \pm 1 \mathrm{mCi}$ of 99mTc-HMPAO (Ceretec, GE-HealthCare, UK), injected into a previously placed intravenous line with the subject supine at rest, with eyes open, in a darkened room, and with ambient white noise. SPECT images were obtained with the Ceraspect brain camera (Digital Scintigraphics, Inc., Waltham, MA), which consists of a single annular sodium iodide crystal and a rotating parallel hole collimator. Spatial resolution is $8.2 \mathrm{~mm}$ full width at halfmaximum (FWHM) at the center of the field of view for $99 \mathrm{mTc}$. The acquisition time was $15 \mathrm{~s}$ per projection for a total acquisition time of $30 \mathrm{~min}$. Data sets were corrected for attenuation and reconstructed with filtered backprojection, using a Butterworth filter.

\section{Data Analysis}

\section{Image analysis}

SPECT data were analyzed using a voxel-based univariate method, Statistical Parametric Mapping (SPM2, Wellcome Department of Cognitive Neurology, Functional Imaging Laboratory, London; Friston et al., 1995). Each data set was spatially transformed to the SPM SPECT template, smoothed with a $12 \mathrm{~mm}$ FWHM Gaussian kernel, and proportionally scaled to the mean global voxel value. To minimize edge effects, voxels with values less than $80 \%$ of the whole brain mean were excluded. Two-sample $t$ tests (contrasting IQ-MI with IQ-MN, no covariates) were performed in both positive and negative directions (i.e., contrasts $1,-1$, and $-1,1$ ) to identify both increases and decreases in relative perfusion. 
Brain areas reaching a significance threshold of $p<.001$ (uncorrected) were identified in terms of voxel coordinates at the peak significance level and labeled according to Talairach and Tournoux (Talairach \& Tournoux, 1988) after conversion from SPM space (i.e., Montreal Neurological Institute space), using the linear transformations of Brett (www.mrc-cbu.cam.ac.uk/Imaging; Brett et al., 2002). Regions that met the threshold of significance and exceeded 200 voxels in extent were identified by comparing cluster location with a probabilistic atlas (Lancaster et al., 2000).

\section{Neuropsychological analysis}

Statistical analyses were performed using SPSS version 11.5. All tests were two-tailed, with statistical significance set at $\alpha=.05$. Independent-samples $t$ tests were used to measure differences between groups on demographic variables at baseline and neuropsychological tests at baseline and followup. Change scores were derived from converting raw scores to $Z$ scores and subtracting the difference between follow-up performances from baseline performances. Independent sample $t$ tests explored differences in change scores between IQ-MN and IQ-MI groups.

\section{RESULTS}

\section{Neuropsychological Results}

\section{Group differences at baseline}

When IQ-adjusted norms were applied, 10 subjects were designated as IQ-MI and 13 subjects remained as IQ-MN. The mean raw scores of the IQ-MN and IQ-MI groups differed significantly on all SRT memory measures including Total Recall [TR; $t(1,21)=2.903 ; p=.008$ ], Long-Term Storage [LTS; $t(1,21)=3.117 ; p=.005]$, Long-Term Retrieval [LTR; $t(1,21)=3.363 ; p=.003]$, Consistent LongTerm Retrieval [CLTR; $t(1,21)=2.538 ; p=.019$ ], $10-\mathrm{min}$ Delayed Recall [DR; $t(1,21)=3.122 ; p=.005$ ], 30-min Delayed Recall [DR30; $t(1,21)=2.278 ; p=.033$ ], and Recognition Recall [MC30; $t(1,21)=2.773 ; p=.011]$. There were also no significant differences between groups on other neuropsychological tests, including FAS, CAT, BNT, or on the VFDT (see Table 1).

\section{Group differences at follow-up}

Three years later, IQ-MN and IQ-MI groups again differed significantly on all SRT memory measures, including TR $[t(1,21)=4.278 ; p=.000]$, LTS $[t(1,21)=4.452 ; p=$ $.000], \operatorname{LTR}[t(1,21)=4.478 ; p=.000]$, CLTR $[t(1,21)=$ $4.451 ; p=.000], \mathrm{DR}[t(1,21)=3.819 ; p=.001], \mathrm{DR} 30$ $[t(1,21)=3.274 ; p=.004]$, and $\mathrm{MC} 30[t(1,21)=2.568$; $p=.018]$. In addition, a significant difference between groups was observed on the VFDT $[t(1,21)=2.671 ; p=.014]$. There were no significant differences between groups in word fluency, category generation, or naming (see Table 1).

\section{Change score group differences at follow-up}

Independent samples $t$ tests of $Z$ change scores revealed IQ-MI subjects statistically declined from baseline over 3 years in contrast to IQ-MN subjects. These declines occurred on tests of memory for TR $[t(1,21)=2.155 ; p=.043]$ and CLTR $[t(1,21)=2.758 ; p=.012]$ but not LTS, LTR, DR, DR30, or MC30. Significant change was also observed on FAS $[t(1,21)=2.695 ; p=.014]$, with IQ-MN subjects demonstrating a significant improvement in performance in contrast to IQ-MI and on VFDT, with IQ-MI doing worse $[t(1,21)=2.237 ; p=.014]$. There were no significant differences noted on CAT or the BNT (see Figure 1).

\section{Clinical outcome}

CDR scores at 3-year follow-up revealed that, within the IQ-MI group, 6 of 10 IQ-MI subjects declined functionally from a CDR of 0 to a CDR of 0.5 in the memory box score, resulting in a CDR total score of 0.5 . All 13 subjects within the IQ-MN group maintained a CDR of 0 . Thus, a significantly greater proportion $(60 \%)$ of individuals identified as at-risk (IQ-MI) declined, compared to $(0 \%)$ of IQ-MN subjects $\left[\chi^{2}(1, n=23)=10.55 ; p=.001\right]$.

\section{SPECT Results}

Perfusion was significantly reduced in IQ-MI compared to IQ-MN subjects in a large right inferior parietal, superior temporal, insular, and opercular frontal region (2024 voxels, nearest BA 13/22/40/6/44, $p<.008$, corrected for multiple comparisons at the cluster level), a right precuneus region (216 voxels, BA 7), and a right inferior parietal region (239 voxels, BA 39/40; see Table 2 and Figure 2). Smaller clusters of reduced perfusion that did not reach the planned significance threshold were seen in contralateral homologous regions and included left precuneus $(Z=2.96$; $p<$ $.002,103$ voxels, BA7) and left inferior parietal $(Z=2.84$; $p<.002,109$ voxels, BA 40). Perfusion was significantly increased in a left medial frontal, rostral anterior cingulate region (BA 11/12/32; $p<.004$, corrected for multiple comparisons) with the IQ-MI compared to the IQ-MN group (see Table 2 and Figure 2).

\section{DISCUSSION}

The cognitive reserve hypothesis suggests that highly intelligent individuals with the beginnings of AD pathology may not exhibit cognitive impairment, making the diagnosis of early AD difficult. In this study, we explored whether making IQ-adjustments was useful in detecting memory impairments in subjects with high cognitive reserve and whether these memory impairments were associated with SPECT perfusion abnormalities at baseline. We found that using an IQ-adjustment method to account for cognitive reserve in CDR0 subjects was able to identify a subset of individuals with subtle memory impairment who showed evidence of 


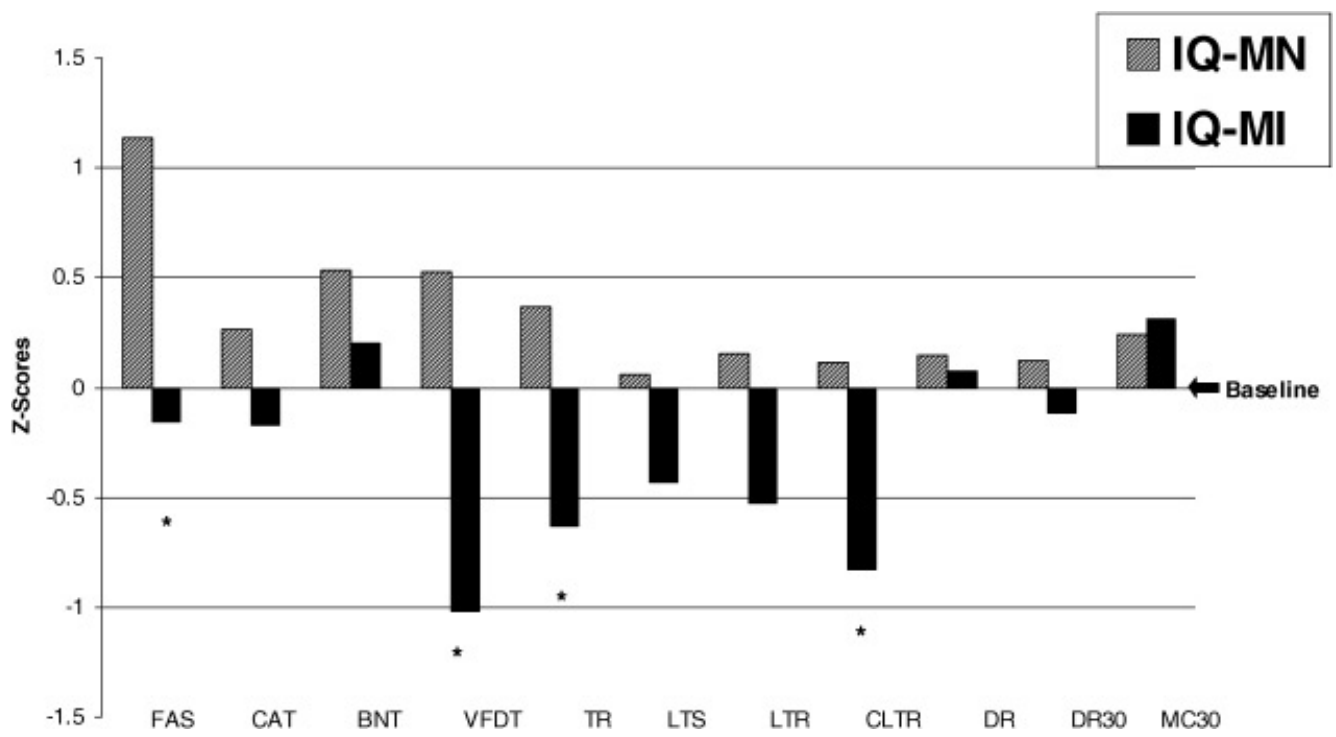

Fig. 1. $Z$ score change from baseline on cognitive tests. Mean $Z$ score changes $( \pm S E$ ) for word generation to the letters F, A, and S (FAS); category generation to animals, vegetables, and fruit (CAT); Boston Naming Test (BNT); Visual Form Discrimination Test (VFDT); and Selective Reminding Test: Total Recall (TR), Long-Term Store (LTS), Long-Term Retrieval (LTR), Continuous Long Term Retrieval (CLTR), 10-min Delayed Recall (DR), 30-min Delayed Recall (DR30), and 30-min Recognition Recall (MC30). Individuals designated as IQ-MI (memory impaired) demonstrated statistically significant changes in phonemic fluency (FAS), visuospatial processing (VFDT), and memory learning (TR) and retrieval (CLTR) compared to the IQ-MN (memory normal) group. ${ }^{*} p<.05$.

cerebral dysfunction on SPECT at baseline in a pattern consistent with AD. These subjects were also more likely to demonstrate subsequent cognitive and functional decline than those without IQ-adjusted abnormalities.

More specifically, IQ-adjustments revealed memory impairment in verbal learning and memory retrieval in 10 CDR0 subjects. Several other longitudinal studies also found that early declines in memory acquisition and retrieval were predictive of conversion to AD (Albert et al., 2001; Collie et al., 2001; Petersen et al., 1994; Stern et al., 1999; Sternberg et al., 2001) and have long been associated with the temporolimbic amnesia commonly found in AD (Albert et al., 2001; Cooper et al., 2004; Monsch et al., 1992; Rentz \& Weintraub, 1999). Three years later, all 10 subjects with

Table 2. Brain areas with significantly different perfusion in IQ-MI subjects compared to IQ-MN subjects

\begin{tabular}{|c|c|c|c|c|c|}
\hline $\begin{array}{l}\text { Extent } \\
\text { (voxels) }\end{array}$ & $\begin{array}{c}Z \\
\text { score }\end{array}$ & $\begin{array}{c}p< \\
\text { (uncorrected) }\end{array}$ & $\begin{array}{c}\mathrm{x}, \mathrm{y}, \mathrm{z} \\
\text { coordinates }\end{array}$ & Region & $\mathrm{BA}$ \\
\hline \multicolumn{6}{|c|}{ Perfusion decrease } \\
\hline 2024 & 4.47 & $.000004 *$ & $44,2,-2$ & $\begin{array}{l}\text { Rt. Insula/ } \\
\text { Sup. Temporal/ } \\
\text { Inf. Parietal/ } \\
\text { Inf. Frontal/ }\end{array}$ & $\begin{array}{l}13 / \\
22 / \\
40 / \\
6 / 44\end{array}$ \\
\hline 216 & 3.74 & .0001 & $24,-71,52$ & Rt. Precuneus & 7 \\
\hline 239 & 3.38 & .0004 & $44,-35,33$ & Rt. Inf. Parietal & $39 / 40$ \\
\hline \multicolumn{6}{|c|}{ Perfusion increase } \\
\hline 2267 & 4.56 & $.000002 * *$ & $-12,24,-10$ & $\begin{array}{l}\text { Lt. Ant. } \\
\text { Cingulate/ } \\
\text { Frontal-subcallosal }\end{array}$ & $\begin{array}{l}11 / \\
12 / \\
32\end{array}$ \\
\hline
\end{tabular}

Note. Perfusion decreases and increases are listed with the corresponding cluster size (extent in voxels), peak voxel $Z$ score, $p$ value (voxel level, uncorrected), peak voxel coordinates, anatomic label, and nearest Brodmann area(s). $\mathrm{MI}=$ memory impaired; $\mathrm{MN}=$ memory normal; $\mathrm{BA}=$ Brodmann area; Rt. = right; Sup. $=$ superior; Inf. $=$ inferior; Lt. $=$ left; Ant. $=$ anterior. ${ }^{*} p=.008$ at the cluster-level, corrected. $* * p=.004$ at the cluster-level, corrected. 


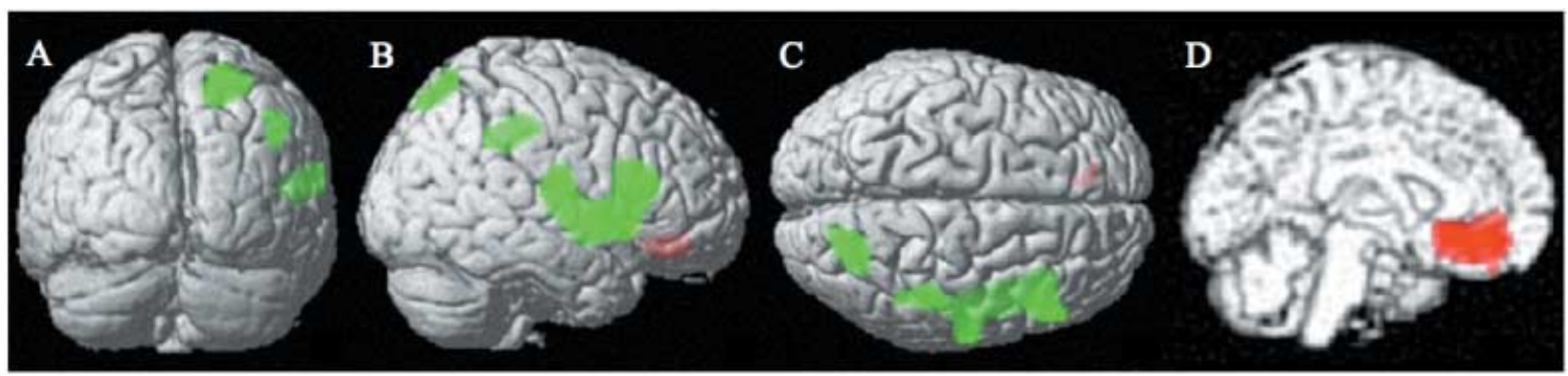

Fig. 2. Lower perfusion in IQ-MI (memory impaired) subjects compared to IQ-MN (memory normal) subjects in parietal/precuneus, temporal, and opercular frontal are shown in posterior (A), right lateral (B), and superior (C) surface projections. Higher perfusion in IQ-MI compared to IQ-MN is shown in the left medial surface projection (D).

baseline IQ-adjusted memory abnormalities showed a significant decline in memory, particularly TR and CLTR compared to IQ-MN. In addition, over half of the IQ-MI subjects also declined in functional status on informant report, whereas none of the IQ-MN subjects declined.

Some may argue that the selective reminding procedures, as used in this study, are not comparable to other measures of episodic memory, because they rely on feedback that is tailored to the individual, that is, only a portion of the list that was not immediately recalled is presented for learning. Therefore, decline on the SRT may be related to executive compromise and not exclusively to the ability to remember words (Loring \& Papanicolaou, 1987). However, in prodromal $\mathrm{AD}$, early executive compromise has been noted by others (Albert et al., 2001) and may explain why SRT procedures were useful in distinguishing our CDR0 subjects who subsequently declined. It is possible that cognitive reserve may modulate aspects of executive function that are beneficial to memory processing during the SRT. However, it would be helpful, in future studies, to make a comparison between episodic learning paradigms and SRT procedures to determine which measures provide greater predictive ability in subjects with high cognitive reserve.

Various proxy measures of cognitive reserve have been explored in several studies, including demographic based regression estimations (Barona et al., 1984), level of education, word reading estimates of premorbid IQ, and more recently, various combinations of education, occupation, and IQ (Andel et al., 2006; Stern et al., 1994, 1995, 2005). In this study, we chose to estimate cognitive reserve using the AMNART, in part because other studies found wordreading estimates of premorbid IQ more sensitive to the neurophysiological effects of AD than other demographic variables (Alexander et al., 1997) or a combination of variables (Bright et al., 2002). However, it is important to note that using an estimate of premorbid ability as a baseline from which to measure impairment presumes that individuals perform at a consistent level across all cognitive domains. Although this is a standard theoretical assumption in neuropsychology (Filskov \& Leli, 1981), there is a potential limitation in interpreting low average neuropsychological test performances as abnormal in persons with superior premorbid ability (Diaz-Asper et al., 2004) and using premorbid IQ as an estimate of premorbid memory (Schretlen et al., 2005). Schretlen et al. (2005) reported that IQ accounts for only 16-28\% of the variance in memory, but this number is based on a cross-section of the age span and may not fully reflect the impact of cognitive reserve on memory in older individuals. As memory declines with aging and $\mathrm{AD}$ pathology, it is likely that individuals need to rely more on compensatory encoding and retrieval strategies, which may be augmented by cognitive reserve. Our study suggests that IQ adjustment of memory scores as a proxy of cognitive reserve may provide a useful way to identify individuals at higher risk for subsequent cognitive decline.

Although we used normative data from Masur et al. (1989) to identify normal memory performance in older individuals, it is important to note that the normative sample from Masur et al. (1989) was older than our sample and much less educated. If more demographically appropriate norms were available, it is possible that our IQ-MI subjects would have been identified as impaired without the use of IQadjustments. However, all of our subjects were CDR0, meaning that they were functioning normal in everyday life and were not clinically impaired.

Moreover, there has been recent discussion as to what cutoff threshold is more sensitive at predicting conversion to AD in at-risk individuals. Petersen et al. (1999) suggests a cutoff of $1.5 S D$ below the mean to designate memory impairment. Busse et al. (2006) reported cutoff scores at 1 $S D$ below the mean were more sensitive in detecting subjects who later converted to AD. It is possible that adjusting the cutoff thresholds might improve the ability to detect early memory changes in subjects with high cognitive reserve. Future studies exploring various methodologies for accounting for cognitive reserve would be helpful, including more sensitive cutoff scores, IQ-adjustments, or developing more contemporary norms.

The IQ-MI subjects who scored greater than $1.5 S D$ below the mean for their ability on measures of memory at baseline demonstrated continued decline 3 years later in contrast to IQ-MN subjects who tended to show improvement. We have previously reported that improvement in cognitive test scores is commonly seen among normal controls (Rentz 
et al., 2004) and may be due to a practice effect. However, many individuals at-risk for $\mathrm{AD}$ do not seem to benefit from practice and demonstrate decline over time. In our sample, these declines were primarily in memory and correspond to the fact that the CDR scores of 6 of 10 IQ-MI subjects demonstrated functional decline related to memory. These findings suggest that IQ-adjustments in memory used to account for cognitive reserve show promise in being able to identify CDR0 subjects who are at risk for both cognitive and functional decline.

Finally, we were interested in learning whether subjects who demonstrated memory impairment for their ability showed abnormalities in functional imaging that were consistent with MCI and AD. Using perfusion SPECT, we found regional functional abnormalities in IQ-MI subjects at baseline in a temporoparietal distribution that is similar to the distribution reported in MCI subjects who subsequently converted to AD (Chetelat et al., 2003; Johnson et al., 1998). Similar findings have also been reported in mild AD (Johnson et al., 2001). More recently, evidence of early AD pathology in these regions was confirmed among MCI patients who came to autopsy (Bradley et al., 2002; Markesbery et al., 2006; Petersen et al., 2006). The temporoparietal perfusion abnormalities noted in our IQ-MI subjects at baseline suggest that $\mathrm{AD}$ pathology may have been present at the time of initial evaluation in normal CDR0 subjects. All of our IQ-MI subjects had the apolipoprotein E3/3 genotype, as we intentionally excluded subjects with the E4 and E2 allele. Interestingly, the pattern of SPECT hypoperfusion showed several overlapping regions with those reported in genetic at-risk subjects (Caselli et al., 2004; Reiman et al., 2001, 2005; Small, 2002); however, the presence of an E4 allele could not explain our findings.

We also found a ventral anterior cingulate region of increased perfusion in IQ-MI subjects compared to IQ-MN subjects. This finding is similar to one we recently reported in CDR 0.5 subjects who were followed and converted to AD within 5 years (Johnson et al., 2007). The increased perfusion in this region might reflect a compensatory response arising along the early trajectory of $\mathrm{AD}$ in response to encroaching pathologic involvement.

It is possible that our SPECT findings were partly due to regional atrophy occurring in IQ-MI subjects, and a limitation of this study is that we did not have complete highresolution brain structural data available to fully assess this possibility. We also realize that this study involved a relatively small number of subjects and may limit the generalizability of our findings.

In summary, we used an IQ-adjustment method to account for cognitive reserve in a highly intelligent sample of older individuals. We found that IQ-adjustments identified early memory changes associated with SPECT hypoperfusion in a pattern consistent with $\mathrm{AD}$ and predicted subsequent future decline. As disease-modifying treatments and imaging markers to detect pathological changes in vivo are entering clinical trials, the accurate identification of individuals at high risk for developing $\mathrm{AD}$ is vital. The findings of this study suggest that neuropsychological methods, which account for cognitive reserve, may improve the ability to identify at-risk individuals with pathological memory changes that portend the trajectory toward $\mathrm{AD}$.

\section{ACKNOWLEDGMENTS}

Parts of this manuscript were presented at the 34th annual meeting of the International Neuropsychological Society in Boston, Massachusetts, and were supported in part by grants from the Alzheimer's Association (IRG-9915 and IRG 02-4153) awarded to K. Johnson, the National Institute on Aging (1R01 AGO17935) awarded to K. Daffner, and The Charles H. Farnsworth Trust, Boston, Massachusetts, awarded to D. Rentz. The authors express their gratitude to Lauren Manning, Elisha Eng, and Jocelyn Woods for their contributions to manuscript preparation and offer special appreciation to all our subjects who gave so generously of their time to make this study possible. The information in this manuscript and the manuscript itself is an original work and has never been published either electronically or in print. No financial conflicts of interests exist with respect to this manuscript.

\section{REFERENCES}

Albert, M.S. (2002). Memory decline: The boundary between aging and age-related disease. Annals of Neurology, 51, 282-284.

Albert, M.S., Moss, M.B., Tanzi, R., \& Jones, K. (2001). Preclinical prediction of AD using neuropsychological tests. Journal of the International Neuropsychological Society, 7, 631-639.

Alexander, G.E., Furey, M.L., Grady, C.L., Pietrini, P., Brady, D.R., Mentis, M.J., \& Schapiro, M.B. (1997). Association of premorbid intellectual function with cerebral metabolism in Alzheimer's disease: Implications for the cognitive reserve hypothesis. American Journal of Psychiatry, 154, 165-172.

Andel, R., Vigen, C., Mack, W.J., Clark, L.J., \& Gatz, M. (2006). The effect of education and occupational complexity on rate of cognitive decline in Alzheimer's patients. Journal of the International Neuropsychological Society, 12, 147-152.

Andreasen, N. \& Blennow, K. (2005). CSF biomarkers for mild cognitive impairment and early Alzheimer's disease. Clinical Neurology and Neurosurgery, 107, 165-173.

Barona, A., Reynolds, C.R., \& Chastain, R. (1984). A demographically based index of premorbid intelligence for the WAIS-R. Journal of Consulting and Clinical Psychology, 52, 885-887.

Bennett, D.A., Schneider, J.A., Arvanitakis, Z., Kelly, J.F., Aggarwal, N.T., Shah, R.C., \& Wilson, R.S. (2006). Neuropathology of older persons without cognitive impairment from two community-based studies. Neurology, 66, 1837-1844.

Benton, A.L., deS Hamsher, K., Varney, N.R., \& Spreen, O. (1983). Contributions to neuropsychological assessment. Oxford: Oxford University Press.

Blessed, G., Tomlinson, B.E., \& Roth, M. (1968). The association between quantitative measures of dementia and of senile change in the cerebral grey matter of elderly subjects. British Journal of Psychiatry, 114, 797-811.

Bradley, K.M., O’Sullivan, V.T., Soper, N.D., Nagy, Z., King, E.M., Smith, A.D., \& Shepstone, B.J. (2002). Cerebral perfusion SPET correlated with Braak pathological stage in Alzheimer's disease. Brain, 125, 1772-1781.

Brett, M., Anton, J.L., Valabregue, R., \& Poline, J.P. (2002). Region of interest analysis using an SPM toolbox [abstract]. Neuroimage, 16, 497. 
Bright, P., Jaldow, E., \& Kopelman, M.D. (2002). The National Adult Reading Test as a measure of premorbid intelligence: A comparison with estimates derived from demographic variables. Journal of the International Neuropsychological Society, 8, 847-854.

Busse, A., Hensel, A., Guhne, U., Angermeyer, M.C., \& RiedelHeller, S.G. (2006). Mild cognitive impairment: Long-term course of four clinical subtypes. Neurology, 67, 2176-2185.

Cabeza, R., Anderson, N.D., Locantore, J.K., \& McIntosh, A.R. (2002). Aging gracefully: Compensatory brain activity in highperforming older adults. Neuroimage, 17, 1394-1402.

Caselli, R.J., Reiman, E.M., Osborne, D., Hentz, J.G., Baxter, L.C., Hernandez, J.L., \& Alexander, G.G. (2004). Longitudinal changes in cognition and behavior in asymptomatic carriers of the APOE e4 allele. Neurology, 62, 1990-1995.

Chetelat, G., Desgranges, B., de la Seyette, V., Viader, F., Eustache, F., \& Baron, J.C. (2003). Mild cognitive impairment: Can FDG-PET predict who is to rapidly convert to Alzheimer's disease? Neurology, 60, 1374-1377.

Collie, A., Maruff, P., Shafiq-Antonacci, R., Smith, M., Hallup, M., Schofield, P., Masters, C.L., \& Currie, J. (2001). Memory decline in healthy older people: Implications for identifying mild cognitive impairment. Neurology, 56, 1533-1538.

Cooper, D.B., Lacritz, L.H., Weiner, M.F., Rosenberg, R.N., \& Cullum, C.M. (2004). Category fluency in mild cognitive impairment: Reduced effect of practice in test-retest conditions. Alzheimer Disease and Associated Disorders, 18, 120-122.

Davis, D.G., Schmitt, F.A., Wekstein, D.R., \& Markesbery, W.R. (1999). Alzheimer neuropathologic alterations in aged cognitively normal subjects. Journal of Neuropathology and Experimental Neurology, 58, 376-388.

Diaz-Asper, C.M., Schretlen, D.J., \& Pearlson, G.D. (2004). How well does IQ predict neuropsychological test performance in normal adults? Journal of the International Neuropsychological Society, 10, 82-90.

Filskov, S.B. \& Leli, D.A. (1981). Assessment of the individual in neuropsychological practice. In S.B. Filskov \& T.J. Boll (Eds.), Handbook of clinical neuropsychology (pp. 545-576). New York, NY: John Wiley \& Sons.

Friedman, R.B., Ferguson, S., Robinson, S., \& Sunderland, T. (1992). Dissociation of mechanisms of reading in Alzheimer's disease. Brain and Language, 43, 400-413.

Friston, K.J., Holmes, A.P., Worsley, K.J., Poline, J.P., Frith, C.D., \& Frackowiak, R.S. (1995). Statistical parametric maps in functional imaging: A general linear approach. Human Brain Mapping, 2, 189-210.

Hall, C.B., Lipton, R.B., Sliwinski, M., \& Stewart, W.F. (2000). A change point model for estimating the onset of cognitive decline in preclinical Alzheimer's disease. Statistics in Medicine, 19, $1555-1566$.

Hyman, B.T., Gomez-Isla, T., Briggs, M., Chung, H., Nicholas, S., Kohout, F., \& Wallace, R. (1996). Apolipoprotein E and cognitive change in an elderly population. Annals of Neurology, 40, 55-66.

Johnson, K.A. \& Albert, M.S. (2000). Perfusion abnormalities in prodromal AD. Neurobiology of Aging, 21, 289-292.

Johnson, K.A., Jones, K., Holman, B.L., Becker, J.A., Spiers, P.A., Satlin, A., \& Albert, M.S. (1998). Preclinical prediction of Alzheimer's disease using SPECT. Neurology, 50, 1563-1571.

Johnson, K.A., Lopera, F., Jones, K., Becker, A., Sperling, R., Hilson, J., Londono, J., Siegert, I., Arcos, M., Moreno, S., Madrigal, L., Ossa, J., Pineda, N., Ardila, A., Roselli, M., Albert,
M.S., Kosik, K.S., \& Rios, A. (2001). Presenilin-1-associated abnormalities in regional cerebral perfusion. Neurology, 56, $1545-1551$.

Johnson, K.A., Moran, E.K., Becker, J.A., Fischman, A.J., \& Albert, M.S. (2007). SPECT perfusion differences in mild cognitive impairment. Journal of Neurology, Neurosurgery, and Psychiatry, 78, 240-247.

Kaplan, E., Goodglass, H., \& Weintraub, S. (1983). The Boston Naming Test: Assessment of aphasia and related disorders (2nd ed.) Philadelphia: Lea \& Febiger.

Klunk, W.E., Engler, H., Nordberg, A., Bacskai, B.J., Wang, Y., Price, J.C., Bergstrom, M., Hyman, B.T., Langstrom, B., \& Mathis, C.A. (2003). Imaging the pathology of Alzheimer's disease: Amyloid-imaging with positron emission tomography. Neuroimaging Clinics of North America, 13, 781-789, ix.

Klunk, W.E., Engler, H., Nordberg, A., Wang, Y., Blomqvist, G., Holt, D.P., Bergstrom, M., Savitcheva, I., Huang, G.F., Estrada, S., Ausen, B., Debnath, M.L., Barletta, J., Price, J.C., Sandell, J., Lopresti, B.J., Wall, A., Koivisto, P., Antoni, G., Mathis, C.A., \& Langstrom, B. (2004). Imaging brain amyloid in Alzheimer's disease with Pittsburgh Compound-B. Annals of $\mathrm{Neu}$ rology, 55, 306-319.

Lancaster, J.L., Woldorff, M.G., Parsons, L.M., Liotti, M., Freitas, C.S., Rainey, L., Kochunov, P.V., Nickerson, D., Mikiten, S.A., \& Fox, P.T. (2000). Automated Talairach atlas labels for functional brain mapping. Human Brain Mapping, 10, 120-131.

Loring, D.W. \& Papanicolaou, A.C. (1987). Memory assessment in neuropsychology: Theoretical considerations and practical utility. Journal of Clinical and Experimental Neuropsychology, 9, 340-358.

Markesbery, W.R., Schmitt, F.A., Kryscio, R.J., Davis, D.G., Smith, C.D., \& Wekstein, D.R. (2006). Neuropathologic substrate of mild cognitive impairment. Archives of Neurology, 63, 38-46.

Masur, D.M., Fuld, P.A., Blau, A.D., Crystal, H., \& Aronson, M.K. (1990). Predicting development of dementia in the elderly with the Selective Reminding Test. Journal of Clinical and Experimental Neuropsychology, 12, 529-538.

Masur, D.M., Fuld, P.A., Blau, A.D., Thal, L.J., Levin, H.S., \& Aronson, M.K. (1989). Distinguishing normal and demented elderly with the Selective Reminding Test. Journal of Clinical and Experimental Neuropsychology, 11, 615-630.

Monsch, A.U., Bondi, M.W., Butters, N., Salmon, D., Katzman, R., \& Thal, L.J. (1992). Comparisons of verbal fluency tasks in the detection of dementia of the Alzheimer's type. Archives of Neurology, 49, 1253-1258.

Morris, J.C. (1993). The Clinical Dementia Rating Scale (CDR): Current version and scoring rules. Neurology, 43, 2412-2414.

Morris, J.C., Storandt, M., McKeel, D.W., Rubin, E.H., Price, J.L., Grant, E.A., \& Berg, L. (1996). Cerebral amyloid deposition and diffuse plaques in "normal" aging: Evidence for presymptomatic and very mild Alzheimer's disease. Neurology, 46, 707-719.

Morris, J.C., Storandt, M., Miller, P., McKeel, D., Price, J.L., Rubin, E.H., \& Berg, L. (2001). Mild cognitive impairment represents early-stage Alzheimer's disease. Archives of Neurology, 58, 397-405.

Mortimer, J.A., Borenstein, A.R., Gosche, K.M., \& Snowdon, D.A. (2005). Very early detection of Alzheimer neuropathology and the role of brain reserve in modifying its clinical expression. Journal of Geriatric Psychiatry and Neurology, 18, 218-223.

Mungas, D., Reed, B.R., Jagust, W.J., DeCarli, C., Mack, W.J., Kramer, J.H., Weiner, M.W., Schuff, N., \& Chui, H.C. (2002). 
Volumetric MRI predicts rate of cognitive decline related to AD and cerebrovascular disease. Neurology, 59, 867-873.

Naugle, R.I., Cullum, C.M., \& Bigler, E.D. (1990). Evaluation of intellectual and memory function among dementia patients who were intellectually superior. The Clinical Neuropsychologist, 4, 355-374.

Nelson, H.E. \& O'Connell, A. (1978). Dementia: The estimation of premorbid intelligence levels using the New Adult Reading Test. Cortex, 14, 234-244.

Nestor, P.J., Fryer, T.D., Ikeda, M., \& Hodges, J.R. (2003). Retrosplenial cortex (BA 29/30) hypometabolism in mild cognitive impairment (prodromal Alzheimer's disease). The European Journal of Neuroscience, 18, 2663-2667.

O'Carroll, R. (1995). The assessment of pre-morbid ability: A critical review. Neurocase, 1, 83-89.

Petersen, R.C., Parisi, J.E., Dickson, D.W., Johnson, K.A., Knopman, D.S., Boeve, B.F., Jicha, G.A., Ivnik, R.J., Smith, G.E., Tangalos, E.G., Braak, H., \& Kokmen, E. (2006). Neuropathologic features of amnestic mild cognitive impairment. Archives of Neurology, 63, 665-672.

Petersen, R.C., Smith, G.E., Ivnik, R.J., Kokmen, E., \& Tangelos, E.G. (1994). Memory function in very early Alzheimer's disease. Neurology, 44, 867-872.

Petersen, R.C., Smith, G.E., Waring, S.C., Ivnik, R.J., Tangelos, E.G., \& Kokmen, E. (1999). Mild cognitive impairment. Clinical characterization and outcome. Archives of Neurology, 56, 303-308.

Price, J.L. \& Morris, J.C. (1999). Tangles and plaques in nondemented aging and "preclinical" Alzheimer's disease. Annals of Neurology, 45, 358-368.

Reiman, E.M., Caselli, R.J., Chen, K., Alexander, G.E., Bandy, D., \& Frost, J. (2001). Declining brain activity in cognitively normal apolipoprotein E4 heterozygotes: A foundation for using positron emission tomography to efficiently test treatments to prevent Alzheimer's disease. Proceedings of the National Academy of Sciences of the United States of America, 98, 3334-3339.

Reiman, E.M., Chen, K., Alexander, G.E., Caselli, R.J., Bandy, D., Osborne, D., Saunders, A.M., \& Hardy, J. (2005). Correlations between apolipoprotein E epsilon4 gene dose and brainimaging measurements of regional hypometabolism. Proceedings of the National Academy of Sciences of the United States of America, 102, 8299-8302.

Rentz, D.M., Huh, T.J., Faust, R.F., Budson, A.B., Scinto, L.F.M., Sperling, R.A., \& Daffner, K.R. (2004). Use of IQ adjusted norms to predict progressive cognitive decline in highly intelligent elders. Neuropsychology, 18, 38-49.

Rentz, D. \& Weintraub, S. (1999). Neuropsychological detection of early probable Alzheimer's disease. In K.R. Daffner \& L.F.M. Scinto (Eds.), Early diagnosis of Alzheimer's disease (pp. 169190). Totowa, NJ: Humana Press.

Richards, M. \& Deary, I.J. (2005). A life course approach to cognitive reserve: A model for cognitive aging and development? Annals of Neurology, 58, 617-622.

Rutschmann, O.T. \& Matchar, D.B. (2002). Usefulness of positron emission tomography in evaluating dementia. Journal of the American Medical Association, 287, 985-986.

Ryan, J. \& Paolo, A. (1992). A screening procedure for estimating premorbid intelligence in the elderly. The Clinical Neuropsychologist, 6, 53-62.

Satz, P. (1993). Brain reserve capacity on symptom onset after brain injury: A formulation and review of evidence for threshold theory. Neuropsychology, 7, 273-295.
Scarmeas, N., Zarahn, E., Anderson, K.E., Habeck, C.G., Hilton, J., Flynn, J., Marder, K.S., Bell, K.L., Sackeim, H.A., Van Heertum, R.L., Moeller, J.R., \& Stern, Y. (2003). Association of life activities with cerebral blood flow in Alzheimer disease: Implications for the cognitive reserve hypothesis. Archives of Neurology, 60, 359-365.

Schmand, B., Geerlings, M., Jonker, C., \& Lindeboom, J. (1998). Reading ability as an estimator of premorbid intelligence: Does it remain stable in emergent dementia? Journal of Clinical and Experimental Neuropsychology, 20, 42-51.

Schmand, B., Smit, J., Geerlings, M., \& Lindeboom, J. (1997). The effects of intelligence and education on the development of dementia. A test of the brain reserve hypothesis. Psychological Medicine, 27, 1337-1344.

Schoonenboom, S.N., Visser, P.J., Mulder, C., Lindeboom, J., Van Elk, E.J., Van Kamp, G.J., \& Scheltens, P.H. (2005). Biomarker profiles and their relation to clinical variables in mild cognitive impairment. Neurocase, 11, 8-13.

Schretlen, D.J., Buffington, A.L., Meyer, S.M., \& Pearlson, G.D. (2005). The use of word-reading to estimate "premorbid" ability in cognitive domains other than intelligence. Journal of the International Neuropsychological Society, 11, 784-787.

Small, G.W. (2002). Use of neuroimaging to detect early brain changes in people at genetic risk for Alzheimer's disease. Advanced Drug Delivery Reviews, 54, 1561-1566.

Stern, Y. (2002). What is cognitive reserve? Theory and research application of the reserve concept. Journal of the International Neuropsychological Society, 8, 448-460.

Stern, Y. (2006). Cognitive reserve and Alzheimer disease. Alzheimer Disease and Associated Disorders, 20, 112-117.

Stern, Y., Albert, S., Tang, M.X., \& Tsai, W.Y. (1999). Rate of memory decline in $\mathrm{AD}$ is related to education and occupation. Neurology, 53, 1942-1947.

Stern, Y., Alexander, G.E., Prohovnik, I., Stricks, L., Link, B., Lennon, M., \& Mayeux, R. (1995). Relationship between lifetime occupation and parietal flow: Implications for a reserve against Alzheimer's disease pathology. Neurology, 45, 55-60.

Stern, Y., Gurlad, B.J., Tatemichi, T., Tang, M.X., Wilder, D., \& Mayeux, R. (1994). Influence of education and occupation on the incidence of Alzheimer's disease. Journal of the American Medical Association, 271, 1004-1010.

Stern, Y., Habeck, C., Moeller, J., Scarmeas, N., Anderson, K.E., Hilton, H.J., Flynn, J., Sackeim, H., \& van Heertum, R. (2005). Brain networks associated with cognitive reserve in healthy young and old adults. Cerebral Cortex, 15, 394-402.

Sternberg, S., Wolfson, C., \& Baumgarten, M. (2001). Undetected dementia in community-dwelling older people: The Canadian Study of Health and Aging. Journal of the American Geriatrics Society, 48, 1430-1434.

Storandt, M., Grant, E.A., Miller, J.P., \& Morris, J.C. (2006). Longitudinal course and neuropathologic outcomes in original vs revised MCI and in pre-MCI. Neurology, 67, 467-473.

Storandt, M., Stone, K., \& LaBarge, E. (1995). Deficits in reading performance in very mild dementia of the Alzheimer type. Neuropsychology, 9, 174-176.

Talairach, J. \& Tournoux, P. (1988). Co-planar stereotaxic atlas of the human brain. 3-Dimensional proportional system: An approach to cerebral imaging. Stuttgart, Germany: George Thieme Verlag.

Tombaugh, T.N. \& Hubley, A.M. (1997). The 60-item Boston Naming Test: Norms for cognitively intact adults aged 25 to 88 
years. Journal of Clinical and Experimental Neuropsychology, 19, 922-932.

WAIS-III-WMS-III Technical Manual. (1997). Wechsler Adult Intelligence Scale-Third Edition. San Antonio, TX: The Psychological Corporation, Harcourt Brace and Company.

Whalley, L.J., Deary, I.J., Appleton, C.L., \& Starr, J.M. (2004). Cognitive reserve and the neurobiology of cognitive aging. Ageing Research Reviews, 3, 369-382.

Wiens, A.N., Bryan, J.E., \& Crossen, J.R. (1993). Estimating WAIS-R FSIQ from National Adult Reading Test-Revised in normal subjects. The Clinical Neuropsychologist, 7, 70-84.

Winblad, B., Palmer, K., Kivipelto, M., Jelic, V., Fratiglioni, L.,
Wahlund, L.O., Nordberg, A., Backman, L., Albert, M., Almkvist, O., Arai, H., Basun, H., Blennow, K., de Leon, M., DeCarli, C., Erkinjuntti, T., Giacobini, E., Graff, C., Hardy, J., Jack, C., Jorm, A., Ritchie, K., van Duijn, C., Visser, P., \& Petersen, R.C. (2004). Mild cognitive impairment-beyond controversies, towards a consensus: Report of the International Working Group on Mild Cognitive Impairment. Journal of Internal Medicine, 256, 240-246.

Yesavage, J.A., Brink, T.L., Rose, T.L., Lum, O., Huang, V., Adey, M., \& Leirer, V.O. (1983). Development and validation of a geriatric depression screening scale. Journal of Psychiatric Research, 17, 37-49. 